\title{
PENGARUH KEADILAN KOMPENSASI TERHADAP KEPUASAN KERJA DAN KINERJA PEGAWAI
}

\author{
Rizki Muslim Hidayat ${ }^{1}$, Heru Kurnianto Tjahjono², Fauziyah $^{3}$ \\ ${ }^{1}$ Universitas Muhammadiyah Yogyakarta \\ hidayatrizki@yahoo.com \\ ${ }^{2}$ Universitas Muhammadiyah Yogyakarta \\ heruutilitas@yahoo.com \\ ${ }^{3}$ Universitas Muhammadiyah Yogyakarta \\ fauziyah_umy@yahoo.com
}

\begin{abstract}
An employee whose has a good performance can help the organization in achieving its intended purpose organizations lead to improvements in public services. Performance of employees, especially in the Civil Registry Office has become problems being discussed by the public (citizen of Tanah Bumbu district) because it concerns on the public service. Based on the phenomenon that occurs low performance caused by the effect of compensation justice such as Distributive Compensation Justice, Procedural Compensation Justice and job satisfaction.

The object of this study is Civil Registry Office in Tanah Bumbu and the subjects are all of the employees whose work in the Civil Registry Office in Tanah Bumbu. This research uses quantitative descriptive analysis approach. The data were collected through observation, questionnaire and interview, then the data was analyze using descriptive analysis and Structural Equation Modeling (SEM) by using smart software Partial Least Squares (PLS).

The results of the study showed that Distributive Compensation Justice and Procedural Compensation Justice had a significant influence on job satisfaction. Job satisfaction, Distributive Compensation Justice and Procedural Compensation Justice also had a significant influence on employees' performance. According to the research results above, it is suggested to the Civil Registry Office of Tanah Bumbu, in order to improve the performance of the employees especially on the variable of Distributive Compensation Justice and Job satisfaction by implementing wage distribution and promotion system which is fair and transparent to the employees so they are satisfied and it can create better performance of the employees.
\end{abstract}

Keywords : Distributive Compensation Justice, Procedural Compansation Justice, Job Satisfaction, Job Performance

(c) 2017 JBTI. All rights reserved

Article history : received 17 Jul 2016; revised 18 Ags 2016; accepted 20 Des 2016

\section{PENDAHULUAN}

Seorang Pegawai yang memiliki kinerja baik dapat membantu organisasi dalam mencapai tujuan yang telah ditetapkan oleh organisasi. Kinerja para Pegawai khususnya di lingkungan Kantor Dinas Kependudukan dan Catatan Sipil Kabupaten Tanah Bumbu menjadi permasalahan yang terus 
menerus diperbincangkan oleh publik (masyarakat Kabupaten Tanah Bumbu). Berakar dari isu tersebut sehingga peneliti tertarik menganalisa permasalahan tersebut.

Berdasarkan pra survei dan wawancara Kantor Dinas Kependudukan dan Catatan Sipil telah mempunyai banyak Pegawai yang berkompeten di bidangnya, walaupun sebagian masih terdapat beberapa Pegawai yang berkinerja rendah seperti kurangnya pengetahuan tentang teknologi dan kurangnya pemahaman terhadap tugas dan tanggung jawab yang diberikan. Yang terlihat pada saat musim penerimaan CPNS periode (2014) dimana sebagian Pegawai masih memiliki keterbatasan atau kendala dalam menjelaskan permasalahan yang terjadi kepada publik terkait gangguan e-KTP sehingga hal tersebut sangat berpengaruh terhadap kinerja Pegawai yang berujung pada kurangnya kualitas pelayanan publik.

Menggali lebih dalam adanya keputusan manajerial yang kurang tepat seperti ketidakjelasan kenaikan jabatan beberapa Pegawai yang seharusnya telah memenuhi persyaratan serta sering terjadi ketidaktepatan waktu dalam pemberian gaji para Pegawai honorer, sehingga dari permasalahan tersebut akan berujung pada pemberian kompensasi yang berpengaruh terhadap kinerja Pegawai.

Pentingnya keadilan kompensasi ini diperhatikan menurut (Tjahjono, 2010) mengatakan bahwa nilai-nilai keadilan merupakan unsur yang sangat penting dalam pengambilan keputusan yang bersifat manajerial. Keputusan tersebut berupa keputusan kompensasi, kenaikan jabatan atau karir, penilaian kinerja, dan keputusan formal manajerial lainnya. Nilai keadilan distributif dan prosedural menjadi hal yang penting dalam pengambilan keputusan tersebut.

Selain itu tingkat kepuasan kerja yang tinggi akan mempengaruhi kinerja, karena merupakan dampak dari keefektifan untuk kesuksesan dalam bekerja, sementara kepuasan yang rendah pada organisasi adalah sebagai rangkaian penurunan moral organisasi dan meningkatnya absensi karyawan (Muhadi, 2007).

Fenomena yang masih terjadi ialah masih kurangnya tingkat kesadaran akan absensi para Pegawai yang berkeliaran pada saat jam kerja, serta fenomena cuti bersama yang telah menjadi kebiasaan para Pegawai memperpanjang masa cuti bersama. Ketidakhadiran Pegawai tanpa keterangan yang jelas akan berdampak terhambatnya pekerjaan yang akan dikerjakan.

\section{KAJIAN TEORI}

\section{A. Keadilan Kompensasi}

Rivai (2009) mengemukakan kompensasi merupakan sesuatu yang diterima karyawan sebagai pengganti kontribusi jasa mereka pada perusahaan. Jenis-jenis kompensasi menurut (Rivai, 2009) terbagi menjadi dua 1) kompensasi finansial : kompensasi langsung (imbalan) dan kompensasi tidak langsung (tunjangan). 2) kompensasi non finansial : terdiri atas karir yang meliputi : jabatan, peluang promosi, pengakuan karya, temuan baru, prestasi istimewa, sedangkan lingkungan kerja meliputi : pujian, bersahabat, nyaman bertugas, menyenangkan dan kondusif.

Keadilan merupakan prinsip penting dalam pemberian kompensasi. Suhartini (2005) mengemukakan keadilan merupakan jantungnya kompensasi. Dengan adanya program kompensasi yang dirasakan adil, maka karyawan akan merasa puas dan sebagai dampaknya tentunya akan termotivasi untuk meningkatkan kinerjanya. Setiap orang pasti menghendaki perlakuan yang adil baik dari sisi distribusi dan prosedur atau disebut sebagai keadilan distributif dan keadilan prosedural, (Tjahjono, 2007).

\section{Keadilan Distributif Kompensasi}

Penelitian tentang keadilan distributif menunjukkan bahwa persepsi individual mengenai 
keadilan terhadap distribusi yang diperolehnya mempengaruhi sikap dan prilaku mereka, (Schminke et al, 1997 dalam Tjahjono, 2010; Palupi, 2013). Dengan kata lain persepsi keadilan distributif menunjuk pada penilaian tentang keadilan hasil yang diterima oleh individu. Keadilan distributif menurut karyawan jika hasil yang mereka terima sama jika dibandingkan dengan hasil yang diterima orang lain. Keadilan ini menunjuk pada keadilan yang diterima karyawan dalam hasil, (Santosa, 2010).

Jika di dalam suatu lingkungan sosial terdapat keadilan distributif yang bisa teraplikasikan secara baik maka akan bisa mengurangi dampak diskriminasi di dalam lingkungan pekerjaan, penerimaan jabatan atau posisi tertentu atas dasar agama atau etnis, dan jika terabaikan maka halhal tersebut bisa mempengaruhi kegiatan organisasi secara struktural, (Haryatmoko, 2002).

\section{Keadilan Prosedural Kompensasi}

Konsep keadilan prosedural menjelaskan bahwa individu tidak hanya melakukan evaluasi terhadap alokasi atau distribusi outcomes, namun juga mengevaluasi terhadap keadilan prosedur untuk menentukan alokasi tersebut, (Tjahjono, 2010). Dengan kata lain keadilan prosedural ialah persepsi keadilan terhadap prosedur yang digunakan untuk membuat keputusan sehingga setiap anggota organisasi merasa terlibat di dalamnya.

Keadilan prosedural menunjuk pada keadilan yang diterima dari prosedur yang digunakan untuk membuat keputusan-keputusan, (Chi \& Han, 2008). Orang merasa setuju jika prosedur yang diadopsi memperlakukan mereka dengan kepedulian dan martabat, membuat prosedur itu mudah diterima bahkan jika orang tidak menyukai hasil dari prosedur tersebut, (Hwei dan Santosa, 2012).

\section{B. Kepuasan Kerja}

Rivai dan Mulyadi (2012) dalam Dahri (2015) menyatakan bahwa kepuasan kerja adalah penilaian dari pekerja tentang seberapa jauh pekerjaannya secara keseluruhan memuaskan kebutuhannya. Sedangkan menurut Luthans (2006) kepuasan kerja adalah keadaan emosi yang senang atau emosi positif yang berasal dari penilaian pekerjaan atau pengalaman kerja seseorang.

Beberapa komponen kepuasan kerja menurut (Luthans, 2006) yaitu :

1. Pembayaran, pegawai mengharapkan pembayaran yang diterima sesuai dengan beban kerja yang mereka dapatkan.

2. Pekerjaan, Pekerjaan yang diberikan dianggap menarik, memberikan kesempatan untuk pembelajaran bagi pegawai serta kesempatan untuk menerima tanggung jawab atas pekerjaan.

3. Kesempatan promosi, adanya kesempatan bagi pegawai untuk maju dan berkembang dalam organisasi, misalnya kesempatan untuk mendapatkan promosi, penghargaan, kenaikan pangkat serta pengembangan individu. Hal ini terkait dengan pengembangan diri setiap pegawai.

4. Atasan, atasan dituntut memiliki kemampuan dalam melakukan pengambilan keputusan yang secara langsung maupun tidak langsung berdampak kepada para bawahannya.

5. Rekan kerja, peranan rekan kerja dalam interaksi yang terjalin antara pegawai mempengaruhi tingkat kepuasan yang dirasakan pegawai.

Wexley dan Yuki (1992), menyatakan bahwa teori-teori kepuasan kerja yang lazim dikenal ada tiga macam yaitu equity theory, discrepancy theory dan two factor theory, teori-teori tersebut secara ringkas dapat dijelaskan sebagai berikut :

\section{Equity Theory (Teori Keadilan)}

Adams (1965), mengemukakan bahwa seseorang akan merasa puas atau tidak puas tergantung 
apakah orang tersebut merasakan adanya keadilan atau tidak atas suatu situasi, khususnya situasi kerja.

\section{Discrepancy Thoery (Teori Ketidaksesuaian)}

Teori ini mengukur kepuasan kerja seseorang dengan menghitung selisih antara sesuatu yang seharusnya dengan kenyataan yang dirasakan.

\section{Two Factor Theory (Teori Dua Faktor)}

Herzberg (1996), menyatakan bahwa kepuasan kerja dan ketidakpuasan kerja merupakan hal yang berbeda dan keduanya tidak merupakan suatu variabel yang kontinyu.

Menurut teori Herzberg (1996), terdapat dua faktor yang menyebabkan kepuasan dan ketidakpuasan yaitu :

Faktor motivator merupakan karakteristik pekerjaan berkaitan dengan kepuasan

1) pekerjaan yaitu sejumlah kebutuhan yang apabila dipenuhi akan menimbulkan kepuasan tetapi jika tidak dipenuhi akan mengurangi kepuasan.

2) Faktor Hygiene merupakan karakteristik pekerjaan berkaitan dengan ketidakpuasan pekerjaan yaitu sejumlah kebutuhan yang apabila dipenuhi tidak akan meningkatkan motivasi, tetapi jika tidak depenuhi akan menimbulkan kepuasan.

\section{Kinerja}

Kinerja karyawan adalah yang mempengaruhi seberapa banyak mereka memberikan kontribusi kepada organisas (Nugraha, 2014), yang meliputi kualitas output, kuantitas output, jangka waktu output, kehadiran di tempat kerja dan sikap kooperatif (bekerja sama).

Nugraha (2014), mengemukakan kinerja karyawan dapat dikelompokkan ke dalam beberapa tingkatan, yaitu tingkatan kinerja tinggi, menengah dan rendah, dapat juga dikelompokkan melampaui target, sesuai target dan di bawah target. Kinerja yang tinggi dapat tercapai karena kepercayaan (trust) timbal balik yang tinggi diantara anggota-anggota artinya para anggota mempercayai integritas, karakteristik dan kemampuan setiap anggota lain.

\section{Hipotesis Dan Hubungan Antara Variabel}

\section{Tabel. 1.}

Hubungan Keadilan Disrtibutif Kompensasi dan Keadilan Prosedural Kompensasi terhadap Kepuasan Kerja

\begin{tabular}{|c|c|c|}
\hline Peneliti & Variabel & Hasil \\
\hline $\begin{array}{c}\text { Tjahjono, H.K. } \\
\text { (2011) } \\
\text { Tjahjono, H.K., } \\
\text { Palupi, M. \& } \\
\text { Dirgahayu, P. } \\
\text { (2015) } \\
\text { Tjahjono, H.K., } \\
\text { Palupi, M \& } \\
\text { Yuasmara, P.G. } \\
\text { (2015) }\end{array}$ & $\begin{array}{ll}\text { 1) } & \text { Kepuasan Kerja } \\
\text { 2) } & \text { Keadilan Distributif } \\
& \text { Kompensasi } \\
\text { 3) } & \text { Keadilan Prosedural } \\
& \text { Kompensasi }\end{array}$ & $\begin{array}{l}\text { Keadilan distibutif kompensasi berpengaruh positif } \\
\text { signifikan terhadap kepuasan. } \\
\text { Keadilan prosedural kompensasi berpengaruh positif } \\
\text { signifikan terhadap kepuasan. }\end{array}$ \\
\hline
\end{tabular}


Berdasarkan hasil penelitian Tabel di atas maka dapat dirumuskan hipotesis sebagai berikut :

H1 : Keadilan distributif kompensasi berpengaruh positif terhadap kepuasan kerja.

H2 : Keadilan prosedural kompensasi berpengaruh positif terhadap kepuasan kerja

Tabel. 2.

Hubungan Kepuasan Kerja terhadap Kinerja

\begin{tabular}{|c|l|l|}
\hline Peneliti & \multicolumn{1}{|c|}{ Variabel } & \multicolumn{1}{c|}{ Hasil } \\
\hline $\begin{array}{c}\text { Ida Ayu } \\
\text { Brahmasari }\end{array}$ & 1) Motivasi Kerja & $\begin{array}{l}\text { Hasil penelitian ini membuktikan bahwa kepuasan kerja } \\
\text { karyawan berpengaruh positif dan signifikan terhadap } \\
\text { kinerja perusahaan, artinya bahwa secara umum } \\
\text { kepuasan kerja karyawan yang tinggi akan mampu } \\
\text { meningkatkan kinerja perusahaan. }\end{array}$ \\
$\begin{array}{c}\text { Agus } \\
\text { Suprayetno }\end{array}$ & 3) Budaya Organisasi \\
$(2008)$ & 5) Kinerja & \\
\hline
\end{tabular}

Berdasarkan hasil penelitian Tabel di atas maka dapat dirumuskan hipotesis sebagai berikut :

H3 : Kepuasan kerja berpengaruh positif terhadap kinerja.

Tabel. 3.

Hubungan Keadilan Disrtibutif Kompensasi dan Keadilan Prosedural Kompensasi terhadap Kinerja

\begin{tabular}{|c|c|c|}
\hline Peneliti & Variabel & Hasil \\
\hline $\begin{array}{l}\text { Tjahjono } \\
\text { (2008) }\end{array}$ & $\begin{array}{l}\text { 1) Keadilan Disributif } \\
\text { 2) Keadilan Prosedural } \\
\text { 3) Teknik Meta Analisis }\end{array}$ & $\begin{array}{l}\text { Hasil konsep ini menjelaskan bahwa personal outcomes } \\
\text { keadilan distributif memiliki keeratan yang lebih baik } \\
\text { daripada keadilan prosedural. } \\
\text { Sedangkan organizational outcomes keadilan prosedural } \\
\text { memiliki keeratan yang lebih baik daripada keadilan } \\
\text { distributif. Personal outcomes dan organizational } \\
\text { outcomes disini dijelaskan menurut Tjahjono (2010), } \\
\text { berarti : } \\
\text { personal outcomes ialah (berkaitan dengan sesuatu yang } \\
\text { diperoleh karyawan) umumnya dalam berbagai } \\
\text { penelitian psikologi organisasi dan manajemen SDM } \\
\text { diproksi dengan kepuasan karyawan yang merupakan } \\
\text { reaksi dan sikap pada kebijakan organisasi seperti, } \\
\text { kebijakan kompensasi, kebijakan karir, kebijakan } \\
\text { penilaian kinerja dan lain-lain. } \\
\text { organizational outcomes ialah (berkaitan dengan sesuatu } \\
\text { yang diperoleh organisasi) umumnya dalam penelitian } \\
\text { diproksi dengan komitmen, produktifitas dan kinerja. }\end{array}$ \\
\hline
\end{tabular}

Berdasarkan hasil penelitian Tabel di atas maka dapat dirumuskan hipotesis sebagai berikut :

H4 : Keadilan distributif kompensasi berpengaruh positif terhadap kinerja.

H5 : Keadilan prosedural kompensasi berpengaruh positif terhadap kinerja. 


\section{E. Model Penelitian}

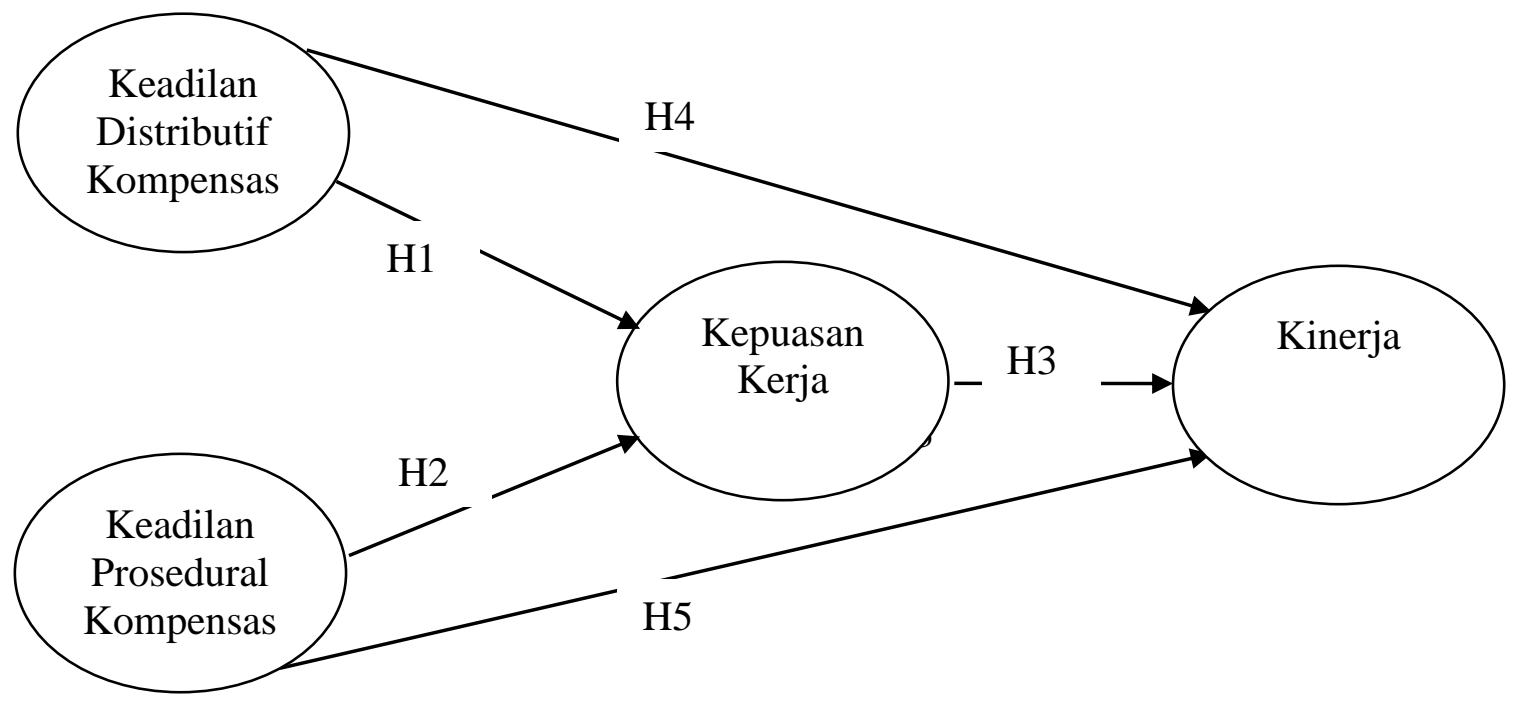

\section{METODE PENELITIAN}

\section{A. Obyek dan Subyek Penelitian}

Obyek penelitian adalah Kantor Dinas Kependudukan dan Catatan Sipil Kabupaten Tanah Bumbu. Subyek dalam penelitian ini adalah Pegawai yang bekerja di lingkungan Kantor Dinas Kependudukan dan Catatan Sipil Kabupaten Tanah Bumbu.

\section{B. Teknik Pengambilan Sampel dan Jumlah Sampel}

Populasi yang digunakan adalah seluruh Pegawai di lingkungan Kantor Dinas Kependudukan dan Catatan Sipil Kabupaten Tanah Bumbu sebanyak 43 orang.

\section{Definisi Operasional dan Pengukuran Variabel}

Tabel. 4.

Definisi Operasional dan Pengukuran Variabel

\begin{tabular}{|c|c|c|}
\hline Variabel & Definisi dan Pengukuran Variabel & Indikator \\
\hline $\begin{array}{c}\text { Keadilan } \\
\text { Distributif } \\
\text { Kompensasi }\end{array}$ & $\begin{array}{l}\text { Menunjukkan persepsi individual mengenai } \\
\text { keadilan terhadap distribusi kompensasi yang } \\
\text { diperolehnya mempengaruhi sikap dan prilaku } \\
\text { mereka, (Schminke et al, } 1997 \text { dalam Tjahjono, } \\
\text { 2010). Dengan kata lain persepsi keadilan } \\
\text { distributif kompensasi menunjuk pada penilaian } \\
\text { tentang keadilan hasil yang diterima oleh } \\
\text { individu. } \\
\text { Perhitungan menggunakan instrument penelitian } \\
\text { yang merujuk pada (Leventhal, 1976 dan } \\
\text { Colquitt, 2001 dimodifikasi Tjahjono, 2008). }\end{array}$ & \begin{tabular}{|l} 
1. \\
Pemberian kompensasi \\
berdasarkan usaha individu. \\
Pemberian kompensasi \\
sesuai dengan yang \\
dilakukan individu terhadap \\
organisasi. \\
3. \\
Pemberian kompensasi \\
menggambarkan yang \\
diberikan individu kepada \\
organisasi. \\
4.
\end{tabular} \\
\hline
\end{tabular}




\begin{tabular}{|c|c|c|}
\hline $\begin{array}{c}\text { Keadilan } \\
\text { Prosedural } \\
\text { Kompensasi }\end{array}$ & $\begin{array}{l}\text { Menjelaskan bahwa individu tidak hanya } \\
\text { melakukan evaluasi terhadap alokasi atau } \\
\text { distribusi outcomes, namun juga mengevaluasi } \\
\text { terhadap keadilan prosedur untuk menentukan } \\
\text { alokasi tersebut (Tjahjono, 2010). Dengan kata } \\
\text { lain keadilan prosedural kompensasi menunjuk } \\
\text { pada persepsi keadilan terhadap prosedur yang } \\
\text { digunakan membuat keputusan untuk } \\
\text { mendistribusikan kompensasi. } \\
\text { Perhitungan menggunakan instrument penelitian } \\
\text { yang merujuk pada (Leventhal, 1976 dan } \\
\text { Colquitt, 2001 dimodifikasi Tjahjono, 2008). }\end{array}$ & 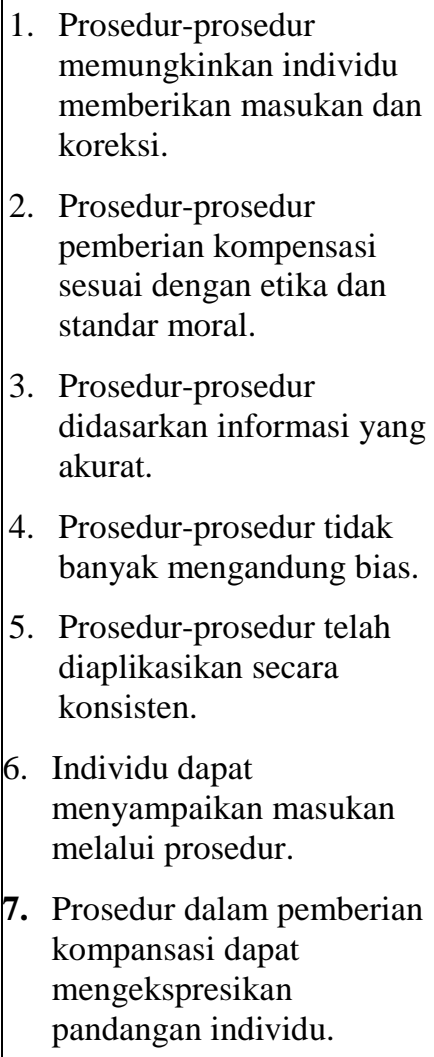 \\
\hline $\begin{array}{c}\text { Kepuasan } \\
\text { Kerja }\end{array}$ & $\begin{array}{l}\text { Keadaan emosi yang senang atau emosi positif } \\
\text { yang berasal dari penilaian pekerjaan atau } \\
\text { pengalaman kerja seseorang, (Luthans, 2006). } \\
\text { Dengan kata lain kepuasan kerja menggambarkan } \\
\text { kesesuaian harapan yang timbul dengan imbalan } \\
\text { yang didapatkan dari pekerjaannya. } \\
\text { Pengukuran dilakukan dengan menggunakan } 6 \\
\text { item pertanyaan yang dikembangkan (Luthans, } \\
2006 \text { dalam Dahri, 2015). }\end{array}$ & $\begin{array}{ll}\text { 1. } & \text { Pembayaran (pay). } \\
\text { 2. } & \text { Pekerjaan (job). } \\
\text { 3. } & \text { Kesempatan promosi } \\
\text { (promotion opportunities). } & \text {. } \\
\text { 4. } & \text { Atasan (supervisor). } \\
\text { 5. } & \text { Rekan kerja (co-workers). } \\
\text { 6. } & \text { Kebijakan, prosedur dan } \\
\text { aturan (operating } \\
\text { Procedures). }\end{array}$ \\
\hline Kinerja & $\begin{array}{l}\text { Pada dasarnya adalah apa yang dilakukan atau } \\
\text { tidak dilakukan karyawan, (Jackson, } 2002 \text { dalam } \\
\text { Nugraha, 2014). Dengan kata lain kinerja adalah } \\
\text { yang mempengaruhi seberapa banyak karyawan } \\
\text { memberikan kontribusi kepada organisasi. } \\
\text { Pengukuran dilakukan dengan menggunakan } \\
\text { model dari (Mathis dan Jackson, } 2002 \text { dalam } \\
\text { Nugraha, 2014). }\end{array}$ & $\begin{array}{l}\text { 1. Kualitas output. } \\
\text { 2. Kuantitas output. } \\
\text { 3. Jangka waktu output. } \\
\text { 4. Kehadiran di tempat kerja. } \\
\text { 5. Sikap kooperatif. }\end{array}$ \\
\hline
\end{tabular}

\section{Teknik Analisis Data}

Menggunakan analisis deskriptif dan model persamaan struktural Structural Equation Modeling (SEM) dengan menggunakan software smart PLS (Partial Least Squares). 


\section{ANALISIS DATA DAN HASIL PENELITIAN}

\section{A. Analisis Deskriptif Variabel}

Tabel. 5.

Kategori Variabel Penelitian

\begin{tabular}{|l|c|c|c|}
\hline \multicolumn{1}{|c|}{ Variabel } & Kode & Mean & Kategori \\
\hline Keadilan Distributif Kompensasi & KDK & 3.70 & Baik \\
\hline Keadilan Prosedural Kompensasi & KPK & 3.84 & Baik \\
\hline Kepuasan Kerja & KK & 3.72 & Baik \\
\hline Kinerja & K & 3.81 & Baik \\
\hline
\end{tabular}

Sumber : data primer yang diolah (2016)

Variabel keadilan distributif kompensasi bahwa responden penelitian sudah merasakan adanya keadilan distributif dalam pembagian kompensasi sesuai dengan pekerjaannya yaitu dengan nilai rata-rata skor mean sebesar 3.70 yang masuk dalam kategori keadilan distributif kompensasi dengan nilai baik.

Variabel keadilan prosedural kompensasi bahwa responden penelitian sudah merasakan adanya keadilan prosedural dalam prosedur penentuan kompensasi sesuai dengan golongan, masa kerja dan beban pekerjaannya yaitu dengan nilai rata-rata skor mean sebesar 3.84 yang masuk dalam kategori keadilan prosedural kompensasi dengan nilai baik.

Variabel kepuasan kerja bahwa responden penelitian sudah merasakan kepuasan yang tinggi dalam melaksanakan pekerjaannya yaitu dengan nilai rata-rata skor mean sebesar 3.72 yang masuk dalam kategori kepuasan kerja dengan nilai baik.

Variabel kinerja bahwa responden penelitian telah memberikan kontribusi baik kepada Instansi serta berkinerja baik dalam melaksanakan pekerjaannya yaitu dengan nilai rata-rata skor mean sebesar 3.81 yang masuk dalam kategori kinerja dengan nilai baik.

\section{B. Uji Validitas Data}

a. Convergent Validity

Dalam penelitian ini digunakan batas loading factor sebesar 0.50, (Ghozali, 2006) :

Tabel. 6.

Validitas Skala Keadilan Disributif Kompensasi

\begin{tabular}{|c|c|c|c|c|}
\hline Variabel & KDK1 & KDK2 & KDK3 & KDK4 \\
\hline Loading Factor & 0.758021 & 0.817987 & 0.818134 & 0.802240 \\
\hline
\end{tabular}

Sumber : data primer yang diolah (2016) 
Berdasarkan Tabel di atas masing-masing item pertanyaan kuesioner pada variabel Keadilan Distributif Kompensasi pada penelitian telah memenuhi convergent validity karena seluruhnya memiliki nilai loading factor diatas 0.50. Maka dapat dikatakan instrumen (kuesioner) penelitian yang digunakan untuk mengukur Keadilan Distributif Kompensasi dinyatakan "valid" atau memenuhi convergent validity dan teruji keabsahannya sehingga dapat digunakan dalam penelitian selanjutnya.

Tabel. 7.

Validitas Skala Keadilan Prosedural Kompensasi

\begin{tabular}{|c|c|c|c|c|c|c|c|}
\hline Variabel & KPK1 & KPK2 & KPK3 & KPK4 & KPK5 & KPK6 & KPK7 \\
\hline Loading Factor & 0.808251 & 0.790934 & 0.790510 & 0.658198 & 0.698581 & 0.714055 & 0.740136 \\
\hline
\end{tabular}

Sumber : data primer yang diolah (2016)

Berdasarkan Tabel di atas masing-masing item pertanyaan kuesioner pada variabel Keadilan Prosedural Kompensasi pada penelitian telah memenuhi convergent validity karena seluruhnya memiliki nilai loading factor diatas 0.50. Maka dapat dikatakan instrumen (kuesioner) penelitian yang digunakan untuk mengukur Keadilan Prosedural Kompensasi dinyatakan "valid" atau memenuhi convergent validity dan teruji keabsahannya sehingga dapat digunakan dalam penelitian selanjutnya.

Tabel. 8.

Validitas Skala Kepuasan Kerja

\begin{tabular}{|c|c|c|c|c|c|c|}
\hline Variabel & KK1 & KK2 & KK3 & KK4 & KK5 & KK6 \\
\hline Loading Factor & 0.697937 & 0.810120 & 0.876425 & 0.760398 & 0.897018 & 0.820945 \\
\hline
\end{tabular}

Sumber : data primer yang diolah (2016)

Berdasarkan Tabel di atas masing-masing item pertanyaan kuesioner pada variabel Kepuasan Kerja pada penelitian telah memenuhi convergent validity karena seluruhnya memiliki nilai loading factor diatas 0.50. Maka dapat dikatakan instrumen (kuesioner) penelitian yang digunakan untuk mengukur Kepuasan Kerja dinyatakan "valid" atau memenuhi convergent validity dan teruji keabsahannya sehingga dapat digunakan dalam penelitian selanjutnya.

Tabel. 9.

Validitas Skala Kinerja

\begin{tabular}{|c|c|c|c|}
\hline Variabel & Loading Factor & Variabel & Loading Factor \\
\hline K1 & 0.727642 & K11 & 0.709963 \\
\hline K2 & 0.688774 & K12 & 0.726867 \\
\hline K3 & 0.779835 & K13 & 0.726210 \\
\hline K4 & 0.697673 & K14 & 0.756386 \\
\hline K5 & 0.730185 & K15 & 0.763205 \\
\hline
\end{tabular}




\begin{tabular}{|c|c|c|c|}
\hline K6 & 0.779935 & K16 & 0.705092 \\
\hline K7 & 0.818211 & K17 & 0.686117 \\
\hline K8 & 0.740579 & \multicolumn{2}{|}{} \\
\cline { 1 - 2 } K9 & 0.701218 & & \\
K10 & 0.687715 & & \\
\end{tabular}

Sumber : data primer yang diolah (2016)

Berdasarkan Tabel masing-masing item pertanyaan kuesioner pada variabel Kinerja pada penelitian telah memenuhi convergent validity karena seluruhnya memiliki nilai loading factor diatas 0.50. Maka dapat dikatakan instrumen (kuesioner) penelitian yang digunakan untuk mengukur Kinerja dinyatakan "valid" atau memenuhi convergent validity dan teruji keabsahannya sehingga dapat digunakan dalam penelitian selanjutnya.

\section{b. Discriminant Validity}

Model dikatakan mempunyai discriminant validity yang baik jika setiap nilai loading indikator dari sebuah variabel laten lebih besar berkorelasi dengan variabel laten tersebut dibanding bila dikorelasikan dengan variabel laten lainnya :

Tabel. 10

Nilai Discriminant Validity (Cross Loading)

\begin{tabular}{|c|c|c|c|c|}
\hline Indikator & K & KDK & KK & KPK \\
\hline K1 & $\mathbf{0 . 7 2 7 6 4 2}$ & 0.359828 & 0.553385 & 0.474576 \\
\hline K2 & $\mathbf{0 . 6 8 8 7 7 4}$ & 0.512296 & 0.432293 & 0.399209 \\
\hline K3 & $\mathbf{0 . 7 7 9 8 3 5}$ & 0.454855 & 0.511003 & 0.479850 \\
\hline K4 & $\mathbf{0 . 6 9 7 6 7 3}$ & 0.375028 & 0.417985 & 0.304364 \\
\hline K5 & $\mathbf{0 . 7 3 0 1 8 5}$ & 0.466105 & 0.499601 & 0.417483 \\
\hline K6 & $\mathbf{0 . 7 7 9 9 3 5}$ & 0.468635 & 0.585111 & 0.338679 \\
\hline K7 & $\mathbf{0 . 8 1 8 2 1 1}$ & 0.471950 & 0.456186 & 0.582768 \\
\hline K8 & $\mathbf{0 . 7 4 0 5 7 9}$ & 0.346381 & 0.567744 & 0.607352 \\
\hline $\mathbf{0 . 7 0 1 2 1 8}$ & 0.495343 & 0.399681 & 0.353094 \\
\hline $\mathbf{0 . 6 8 7 7 1 5}$ & 0.462709 & 0.379439 & 0.342325 \\
\hline
\end{tabular}




\begin{tabular}{|c|c|c|c|c|}
\hline Indikator & $\mathbf{K}$ & KDK & KK & KPK \\
\hline K11 & 0.709963 & 0.599984 & 0.436256 & 0.354270 \\
\hline K12 & 0.726867 & 0.493650 & 0.592273 & 0.647492 \\
\hline K13 & 0.726210 & 0.609377 & 0.583693 & 0.692472 \\
\hline K14 & 0.756386 & 0.501682 & 0.575769 & 0.412493 \\
\hline K15 & 0.763205 & 0.467703 & 0.512663 & 0.545445 \\
\hline K16 & 0.705092 & 0.486487 & 0.521436 & 0.484295 \\
\hline K17 & 0.686117 & 0.501888 & 0.410984 & 0.426712 \\
\hline KDK1 & 0.433537 & 0.758021 & 0.417326 & 0.280910 \\
\hline KDK2 & 0.466252 & 0.817987 & 0.419406 & 0.230867 \\
\hline KDK3 & 0.660913 & 0.818134 & 0.643826 & 0.611208 \\
\hline KDK4 & 0.471502 & 0.802240 & 0.553881 & 0.486715 \\
\hline KK1 & 0.502551 & 0.528839 & 0.697937 & 0.454710 \\
\hline KK2 & 0.673361 & 0.615463 & 0.810120 & 0.694753 \\
\hline KK3 & 0.558339 & 0.616500 & 0.876425 & 0.482944 \\
\hline KK4 & 0.414483 & 0.379185 & 0.760398 & 0.404209 \\
\hline KK5 & 0.617376 & 0.588634 & 0.897018 & 0.471487 \\
\hline KK6 & 0.514705 & 0.390744 & 0.820945 & 0.473074 \\
\hline KPK1 & 0.627542 & 0.391496 & 0.639153 & 0.808251 \\
\hline KPK2 & 0.476612 & 0.417439 & 0.417296 & 0.790934 \\
\hline KPK3 & 0.499241 & 0.516212 & 0.494172 & 0.790510 \\
\hline KPK4 & 0.322713 & 0.211871 & 0.268346 & 0.658198 \\
\hline KPK5 & 0.385578 & 0.382970 & 0.377420 & 0.698581 \\
\hline КРК6 & 0.427220 & 0.461626 & 0.428608 & 0.714055 \\
\hline
\end{tabular}




\begin{tabular}{|c|c|c|c|c|}
\hline Indikator & K & KDK & KK & KPK \\
\hline KPK7 & 0.538026 & 0.363878 & 0.504193 & $\mathbf{0 . 7 4 0 1 3 6}$ \\
\hline
\end{tabular}

Sumber : data primer yang diolah (2016)

Berdasarkan Tabel nilai loading factor untuk setiap indikator dari masing-masing variabel laten memiliki nilai loading factor yang paling besar dibanding nilai loading factor jika dihubungkan dengan variabel laten lainnya. Hal ini berarti bahwa setiap variabel laten memiliki discriminant validity yang baik.

\section{Uji Reliabilitas Data}

Tabel. 11.

Hasil Uji Reliabilitas Variabel Keadilan Distributif Kompensasi, Keadilan Prosedural Kompensasi, Kepuasan Kerja dan Kinerja

\begin{tabular}{|c|c|c|c|}
\hline Variabel & Indikator & Cronbach's Alpha & Kriteria \\
\hline $\begin{array}{c}\text { Keadilan Distributif } \\
\text { Kompensasi }\end{array}$ & 4 & 0.815851 & Reliabel \\
\hline $\begin{array}{c}\text { Keadilan Prosedural } \\
\text { Kompensasi }\end{array}$ & 7 & 0.866776 & Reliabel \\
\hline Kepuasan Kerja & 6 & 0.896527 & Reliabel \\
\hline Kinerja & 17 & 0.945710 & Sangat Reliabel \\
\hline
\end{tabular}

Sumber : data primer yang diolah (2016)

\section{Pengujian Model Struktural (Inner Model)}

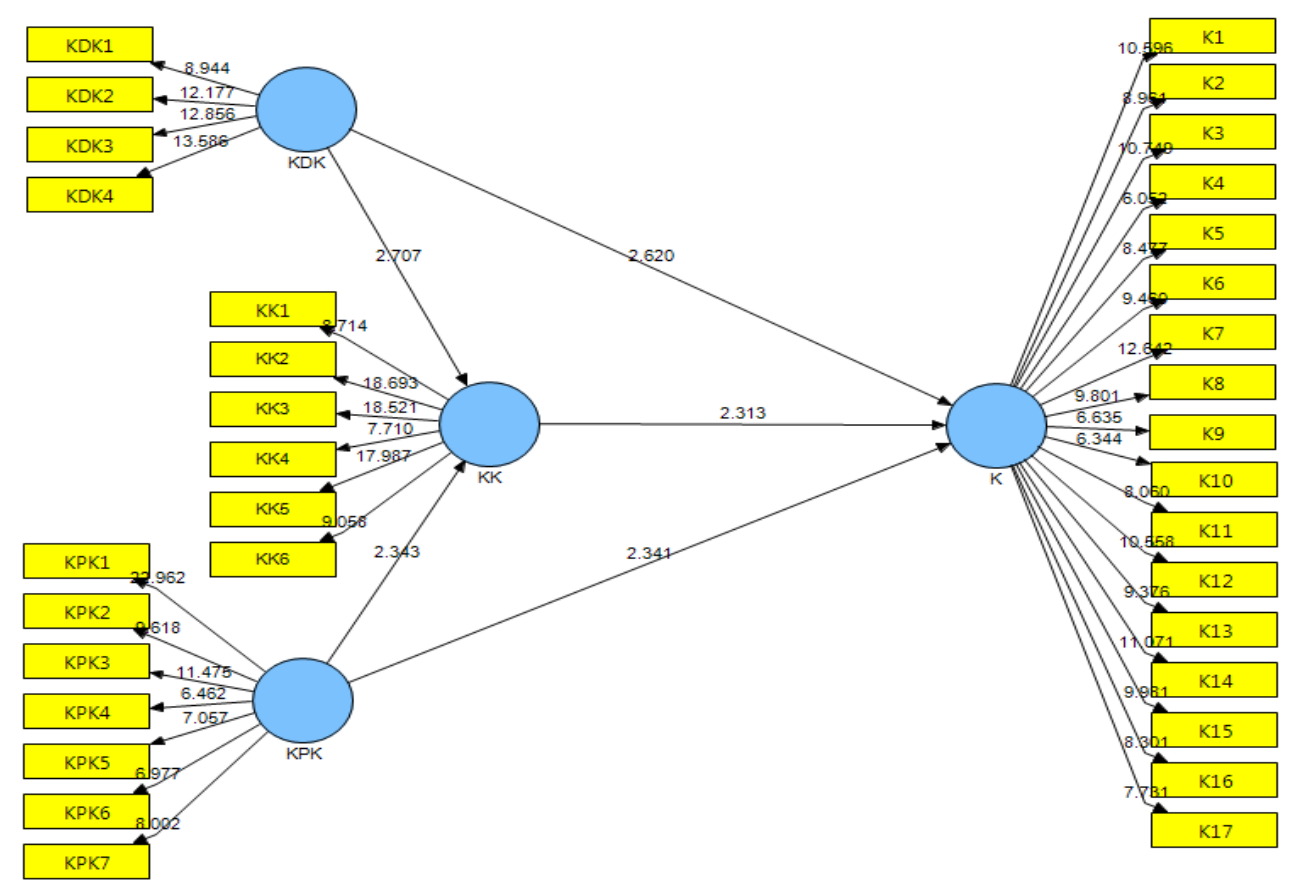


Tabel. 12

Nilai R-Square

\begin{tabular}{|c|c|}
\hline & R Square \\
\hline K & 0.596499 \\
\hline KDK & \\
\hline KK & 0.534808 \\
\hline KPK & \\
\hline
\end{tabular}

Sumber : data primer yang diolah (2016)

Berdasarkan Tabel nilai R-square untuk variabel Kinerja (K) sebesar 0.596. Hal ini berarti bahwa variabel Kinerja dijelaskan oleh variabel Keadilan Distributif Kompensasi (KDK), Keadilan Prosedural Kompensasi (KPK), dan Kepuasan Kerja (KK) sebesar 59.6 \%. Sedangkan nilai Rsquare untuk variabel Kepuasan Kerja (KK) sebesar 0.535 yang berarti bahwa variabel Kepuasan Kerja dijelaskan oleh variabel Keadilan Distributif Kompensasi (KDK) dan Keadilan Prosedural Kompensasi (KPK) sebesar $53.5 \%$.

Evaluasi model konstruk selanjutnya dilakukan dengan menghitung Q-square predictive relevance (Ghozali, 2006) sebagai berikut :

$$
\begin{aligned}
Q^{2} & =1-\left(1-\mathrm{RKK}^{2}\right)\left(1-\mathrm{RK}^{2}\right) \\
& =1-(1-0.535)(1-0.596) \\
& =1-(0.465)(0.404) \\
& =1-0.188 \\
& =0.812
\end{aligned}
$$

Berdasarkan perhitungan tersebut, nilai $Q^{2}$ yang diperoleh sebesar 0.812 yang menunjukkan bahwa model yang dibentuk sudah baik.

\section{E. Pengujian Hipotesis}

Untuk menguji hipotesis yang diajukan, dapat dilihat besarnya nilai t statistik. Apabila nilai $t$ statistik > t tabel, maka hipotesis akan diterima. Hasil estimasi t statistik dapat dilihat pada Tabel 1.13 result for inner weight :

Tabel. 13.

Path Coefficients (Mean, STDEV, T-Values)

\begin{tabular}{|c|c|c|c|c|c|}
\hline & $\begin{array}{c}\text { Original Sample } \\
(\mathbf{O})\end{array}$ & $\begin{array}{c}\text { Sample Mean } \\
(\mathbf{M})\end{array}$ & $\begin{array}{c}\text { Standard Deviation } \\
\text { (STDEV) }\end{array}$ & $\begin{array}{c}\text { Standard Error } \\
\text { (STERR) }\end{array}$ & $\begin{array}{c}\text { T Statistics } \\
(\mid \mathbf{O} / \text { STERR|) }\end{array}$ \\
\hline KDK $\rightarrow \mathbf{K}$ & 0.289935 & 0.295363 & 0.110665 & 0.110665 & 2.619944 \\
\hline
\end{tabular}




\begin{tabular}{|lll|l|l|l|l|l|}
\hline KDK & $\rightarrow$ & KK & 0.449353 & 0.465442 & 0.166019 & 0.166019 & 2.706631 \\
\hline KK & $\rightarrow$ & K & 0.308235 & 0.330634 & 0.133245 & 0.133245 & 2.313301 \\
\hline KPK & $\rightarrow$ & K & 0.301507 & 0.287227 & 0.128814 & 0.128814 & 2.340637 \\
\hline KPK & > & KK & 0.384964 & 0.389077 & 0.164328 & 0.164328 & 2.342657 \\
\hline
\end{tabular}

Sumber : data primer yang diolah (2016)

Berdasarkan Tabel 1.13 dapat dilakukan pengujian terhadap hipotesis penelitian. Pengujian hipotesis menggunakan tingkat signifikansi $5 \%$ dengan $\mathrm{t}$ tabel sebesar $2.018(\mathrm{~N}=43)$ :

a. Pengujian Hipotesis 1. keadilan distributif kompensasi berpengaruh positif terhadap kepuasan kerja. Hasil uji koefisien parameter antara keadilan distributif kompensasi dengan kepuasan kerja menunjukkan nilai koefisien sebesar 0.449 dan nilai $t$ hitung sebesar 2.707. Pada taraf signifikansi $(\alpha)=0.05$, nilai t hitung tersebut lebih besar dibanding nilai $\mathrm{t}$ tabel sebesar 2.018. Hal ini menunjukkan bahwa keadilan distributif kompensasi berpengaruh positif terhadap kepuasan kerja. Sehingga hipotesis pertama (H-1) yang menyatakan keadilan distributif kompensasi berpengaruh positif signifikan terhadap kepuasan kerja, "diterima".

b. Pengujian Hipotesis 2. keadilan prosedural kompensasi berpengaruh positif terhadap kepuasan kerja. Hasil uji koefisien parameter antara keadilan prosedural kompensasi dengan kepuasan kerja menunjukkan nilai koefisien sebesar 0.385 dan nilai t hitung sebesar 2.343. Pada taraf signifikansi $(\alpha)=0.05$, nilai $\mathrm{t}$ hitung tersebut lebih besar dibanding nilai $\mathrm{t}$ tabel sebesar 2.018 . Hal ini menunjukkan bahwa keadilan prosedural kompensasi berpengaruh positif terhadap kepuasan kerja. Sehingga hipotesis kedua (H-2) yang menyatakan keadilan prosedural kompensasi berpengaruh positif signifikan terhadap kepuasan kerja, "diterima".

c. Pengujian Hipotesis 3. kepuasan kerja berpengaruh positif terhadap kinerja. Hasil uji koefisien parameter antara kepuasan kerja dengan kinerja menunjukkan nilai koefisien sebesar 0.308 dan nilai $\mathrm{t}$ hitung sebesar 2.313. Pada taraf signifikansi $(\alpha)=0.05$, nilai $\mathrm{t}$ hitung tersebut lebih besar dibanding nilai t tabel sebesar 2.018. Hal ini menunjukkan bahwa kepuasan kerja berpengaruh positif terhadap kinerja. Sehingga hipotesis ketiga (H-3) yang menyatakan kepuasan kerja berpengaruh positif signifikan terhadap kinerja, "diterima".

d. Pengujian Hipotesis 4. keadilan distributif kompensasi berpengaruh positif terhadap kinerja. Hasil uji koefisien parameter antara keadilan distributif kompensasi dengan kinerja menunjukkan nilai koefisien sebesar 0.290 dan nilai t hitung sebesar 2.620. Pada taraf signifikansi $(\alpha)=0.05$, nilai t hitung tersebut lebih besar dibanding nilai t tabel sebesar 2.018. Hal ini menunjukkan bahwa keadilan distributif kompensasi berpengaruh positif terhadap kinerja. Sehingga hipotesis keempat (H-4) yang menyatakan keadilan distributif kompensasi berpengaruh positif signifikan terhadap kinerja, "diterima".

e. Pengujian Hipotesis 5. keadilan prosedural kompensasi berpengaruh positif terhadap kinerja. Hasil uji koefisien parameter antara keadilan prosedural kompensasi dengan kinerja menunjukkan nilai koefisien sebesar 0.301 dan nilai $t$ hitung sebesar 2.341. Pada taraf signifikansi $(\alpha)=0.05$, nilai $\mathrm{t}$ hitung tersebut lebih kecil dibanding nilai $\mathrm{t}$ tabel sebesar 2.018. Hal ini menunjukkan bahwa keadilan prosedural kompensasi berpengaruh positif terhadap kinerja. Sehingga hipotesis kelima (H-5) yang menyatakan keadilan prosedural kompensasi berpengaruh positif signifikan terhadap kinerja, "diterima". 


\section{KESIMPULAN}

Secara umum hasil penelitian ini mencerminkan kondisi Pegawai sudah dalam kondisi yang baik, artinya ditinjau dari masing-masing variabel yang diteliti yaitu keadilan distributif kompensasi, keadilan prosedural kompensasi, kepuasan kerja dan Kinerja sudah berjalan on the right track. Namun demikian ada beberapa beberapa saran yang diharapkan bisa dijadikan masukan untuk peningkatan kepuasan kerja dan kinerja Pegawai dimasa mendatang dalam upaya meningkatkan efektifitas dalam bekerja, sebagai berikut :

1. Menerapkan prosedur / kebijakan untuk mengalokasikan pendistribusian / pemberian kompensasi seperti (gaji, tunjangan, promosi jabatan dan jenjang karir) secara adil dan transparan hendaknya berdasarkan prinsip keadilan prosedural dan prinsip keadilan distributif sesuai dengan kompetensi, keahlian dan beban kerja bukan berdasarkan like and dislike.

2. Selain memperhatikan nilai-nilai keadilan dalam kompensasi untuk meningkatkan kinerja, perlu diperhatikan juga peran serta para pimpinan yang hendaknya dapat menciptakan hubungan kerja yang harmonis, mendesain iklim kerja yang kondusif agar Pegawai yang berada di lingkungan tersebut merasa nyaman sehingga diharapkan dapat mengurangi tingkat absensi Pegawai serta berusaha menghargai semua hasil kerja yang dicapai agar pekerjaan yang dikerjakan tidak dirasakan sia-sia sehingga dapat meningkatkan kepuasan kerja mereka.

3. Untuk penelitian selanjutnya diharapkan dapat lebih mengembangkan penelitian ini terkhusus yang menyangkut dengan variabel keadilan distributif kompensasi, keadilan prosedural kompensasi, kepuasan kerja dan kinerja dengan menambahkan beberapa faktor lain yang dapat mempengaruhi kepuasan kerja dan kinerja serta pengembangan subyek seperti peningkatan jumlah responden.

\section{DAFTAR PUSTAKA}

Adam, J.S., 1965, 'In Equity In Social Exchanges', Advances In Experimental Social Psychology, Academics Press. Vol. 2, 267 - 300.

Brahmasari, I. A., Dan Suprayetno, A., 2008, 'Pengaruh Motivasi Kerja, Kepemimpinan dan Budaya Organisasi Terhadap Kepuasan Kerja Karyawan serta Dampaknya pada Kinerja Perusahaan" : Studi kasus pada PT. Pei Hai International Wiratama Indonesi, Jurnal Manajemen Dan Kewirausahaan, Vol. 10, No. 2, 124 - 135.

Dahri, N. W., 2015, Peran Mediasi Kepuasan Kerja Pada Model Pengaruh Keadilan Distributif Kompensasi, Keadilan Prosedural Kompensasi, Person-Organizational Fit Terhadap Komitmen Afektif : Survei pada Kantor Wilayah Kementrian Agama Provinsi Sulawesi Barat, Tesis Program Studi Magister Manajemen Universitas Muhammadiyah Yogyakarta, Yogyakarta.

Ghozali, I., 2006, Structural Equation Modeling Metode Alternatif dengan Partial Least Square, Semarang : Badan Penerbit Universitas Diponegoro.

Herzberg., 1996, The Motivation to Work, New York : Wisley \& Sons.

Hwe, She. Dan Santosa, T., Elisabeth, C., 2012, ''Pengaruh Keadilan Prosedural dan Keadilan Distributif Terhadap Komitmen Organisasi’, Jurnal Dinamika Ekonomi dan Bisnis, Vol. 9, No. 2.

Luthans, F., 2006, Prilaku Organisasi : Edisi Sepuluh, Yogyakarta : Andi.

Muhadi., 2007, Analisis Pengaruh Kepuasan Kerja Terhadap Komitmen Organisasional Dalam Mempengaruhi Kinerja Karyawan, Tesis Program Studi Magister Manajemen Universitas Diponegoro, Semarang. 
Nugraha, T. P., 2014, Pengaruh Kecerdasan Intelektual, Kecerdasan Emosional dan Kecerdasan Spiritual Terhadap Kinerja Pegawai Studi Di Kantor Camat Panggarangan, Tesis Program Studi Magister Manajemen Universitas Muhammadiyah Yogyakarta, Yogyakarta.

Palupi, M., 2013, Pengaruh Keadilan Kompensasi, Kebijakan Rotasi, dan Komitmen Afektif pada Perilaku Retaliasi PNS Kantor "X" di Yogyakarta. Jurnal Riset Manajemen dan Bisnis, volume 8, No. 1, th. 2013, hal 15-24.

Rivai, H. V., 2009, Manajemen Sumber Daya Manusia Untuk Perusahaan : Dari Teori Ke Praktik, Jakarta : Raja Grafindo Persada.

Santosa., 2010, Komitmen Organisasi, Kepuasan Kerja, Keterlibatan Kerja, Keadilan Manajerial, Kepercayaan Terhadap Organisasi dan Dampaknya Terhadap Organizational Citizenship Behavior (OCB), Tesis Program Studi Magister Manajemen Universitas Kristen Maranatha, Bandung.

Suhartini., 2005, 'Keadilan Dalam Pemberian Kompensasi'”, Jurnal Siasat Bisnis, No. 4, Vol. 2, $103-114$.

Tjahjono, H. K., 2007, Keadilan Distributif dan Keadilan Prosedural Dinilai Adil Bagi Sebagian Karyawan, Yogyakarta : Universitas Gadjah Mada.

Tjahjono, H. K., 2008, 'Studi Literatur Pengaruh Keadilan Distributif dan Keadilan Prosedural pada Konsekuensinya dengan Teknik Meta Analisis', Karya Ilmiah Dimuat di Jurnal Psikologi, Fakultas Psikologi UGM, Volume 35, No. 1, Juni 2008. ISSN : 0215-8884.

Tjahjono, H. K., 2010, Manajemen Berkeadilan Dan Pengaruhnya Pada Outcomes Perusahaan, Pidato Pengukuhan Jabatan Guru Besar Fakultas Ekonomi Universitas Muhammadiyah Yogyakarta.

Tjahjono, H.K., 2011, The configuration pattern distributive and procedural justice and its consequences to satisfaction. International Journal of Information and Management Sciences, 22(1):87-103

Tjahjono, H.K., 2015, Metode Penelitian Bisnis. VSM MM UMY

Tjahjono, H.K., Palupi, M. \& Dirgahayu, P. (2015). Career perception at the republic indonesian police organization impact of distributive fairness, procedural fairness and career satisfaction. International Journal of Administrative Science \& Organization, 22(2):130135

Tjahjono, H.K., Palupi, M. \& Dirgahayu, P., 2015, Peran pemediasian kepuasan karir pada pengaruh keadilan distributif dan keadilan prosedural karir pada komitmen afektif karyawan swasta di provinsi daerah istimewa yogyakarta. Akmenika, 12(1):563-573

Vroom, V. H., 1999, Work and Motivation, New York : John Wiley and Sons. INC.

Wekley, K.N. Dan Yuki, G.A., 1992, Prilaku Organisasi dan Psikologi Personalia, Jakarta : Rineka Cipta. 